\title{
Isolated papillary muscle hypertrophy in a professional soccer player: the end of an athlete's career?
}

\author{
Cyntia Zulema Machain Leyva', Cuitláhuac Arroyo-Rodríguez²,3, José Roberto Victoria-Nandayapa³, \\ Sergio Ramón Figueroa-Sauceda'
}

'Division of Cardiology, Internal Medicine, Hospital No. 2, High Specialty Medical Unit, Northwest National Medical Center of the Instituto Mexicano del Seguro Social at Ciudad Obregón, Sonora, México

2Departamento de Medicina y Ciencias de la Salud, Universidad de Sonora, Hermosillo, Sonora, México

${ }^{3}$ Cardiology Department, Hospital San José Hermosillo, Sonora, México

\author{
Correspondence to: \\ Cuitláhuac \\ Arroyo-Rodríguez, MD, \\ Cardiology Department, \\ Hospital San José \\ Hermosillo, Sonora, México, \\ Morelos No. 340, Colonia \\ Bachoco, Hermosillo, \\ Sonora, México, CP 83148, \\ phone: +52644 1678937 \\ e-mail: \\ cuitla88@hotmail.com \\ Copyright by the Author(s), \\ 2021 \\ Kardiol Pol. 2021; \\ 79 (10): 1147-1148; \\ DOI: 10.33963/KP.a2021.0063 \\ Received: \\ May 25, 2021 \\ Revision accepted: \\ July 13, 2021 \\ Published online: \\ July 14, 2021
}

\begin{abstract}
A 21-year-old male, a totally asymptomatic professional football player, was referred for a routine cardiovascular check-up. He had no relevant medical history and a positive family history of cardiac, renal, neurologic, or genetic diseases. Physical examination was unremarkable.

His electrocardiogram showed left ventricular hypertrophy, non-pathological Q waves, and asymmetric inverted T-waves in the inferior and lateral leads. Transthoracic echocardiography (TTE) showed concentric hypertrophy, left ventricular ejection fraction of $56 \%$, and global longitudinal strain of $-17 \%$. Remarkably, the papillary muscles were hypertrophied (Figure 1, Supplementary material, Video S1-S3). No intraventricular gradient was provoked with Valsalva maneuver. Diastolic function was normal.
\end{abstract}

On cardiopulmonary stress testing, he achieved 15 metabolic equivalents of task and maximal oxygen consumption of $52.6 \mathrm{ml} / \mathrm{kg} / \mathrm{min}$. Blood pressure response to exercise was normal. No ST-segment deviation nor arrhythmias were induced by the exercise.

No rhythm disturbances were found during 48-hour Holter monitoring that included a training session.

A genetic analysis including the following genes was performed: ACTC1, GLA, MYH7, PLN, TNNC1, TMP1, DES, LAMP2, MYL2, PRKAG2, TNNI3, TTR, FLNC, MYBPC3, MYL3, PTPN11, and TNNT2. No variants with clinical significance were found in the analyzed genes. However, it should be noted that genetic testing is not recommended for risk stratification by recent guidelines [1].

A cardiac magnetic resonance was attempted for tissue characterization and myocardial fibrosis assessment. Unfortunately, it could not be accomplished because the patient became claustrophobic and refused to receive sedation. We recognize this as a limitation; however, this patient had an excellent acoustic window for TTE, and there were no segments with increased wall thickness which could have been of diagnostic value when hypertrophic cardiomyopathy (HCM) is suspected [2].

Deconditioning was recommended, and after 3 months, papillary muscle hypertrophy was not changed on TTE. The patient has remained competitive and asymptomatic for 18 months since his diagnosis and no increase in left ventricular mass nor an increase in papillary muscle hypertrophy have been found on his follow-up TTE.

Papillary muscle hypertrophy $(\mathrm{PMH})$ has been defined as $\mathrm{a} \geq 1.1 \mathrm{~cm}$ diameter of at least one papillary muscle in the horizontal or vertical direction in the parasternal short-axis view [3]. PMH and accessory papillary muscles have been associated with sudden cardiac arrest of unknown cause [4]. Moreover, football is a specific sport that may pose a higher risk for sudden cardiac death because of its highly dynamic and start-stop exercise [1].

A few reports have suggested that isolated $\mathrm{PMH}$ could be an initial form of $\operatorname{HCM}[3,5]$. Conversely, recent guidelines do not consider isolated PMH diagnostic of HCM [2]. Until now, no clear recommendations exist regarding sport participation in high-endurance athletes with isolated $\mathrm{PMH}$. In our case, it was decided to allow the patient to to continue competitive sports participation with close monitoring due to (1) the favorable cardiopulmonary stress test 


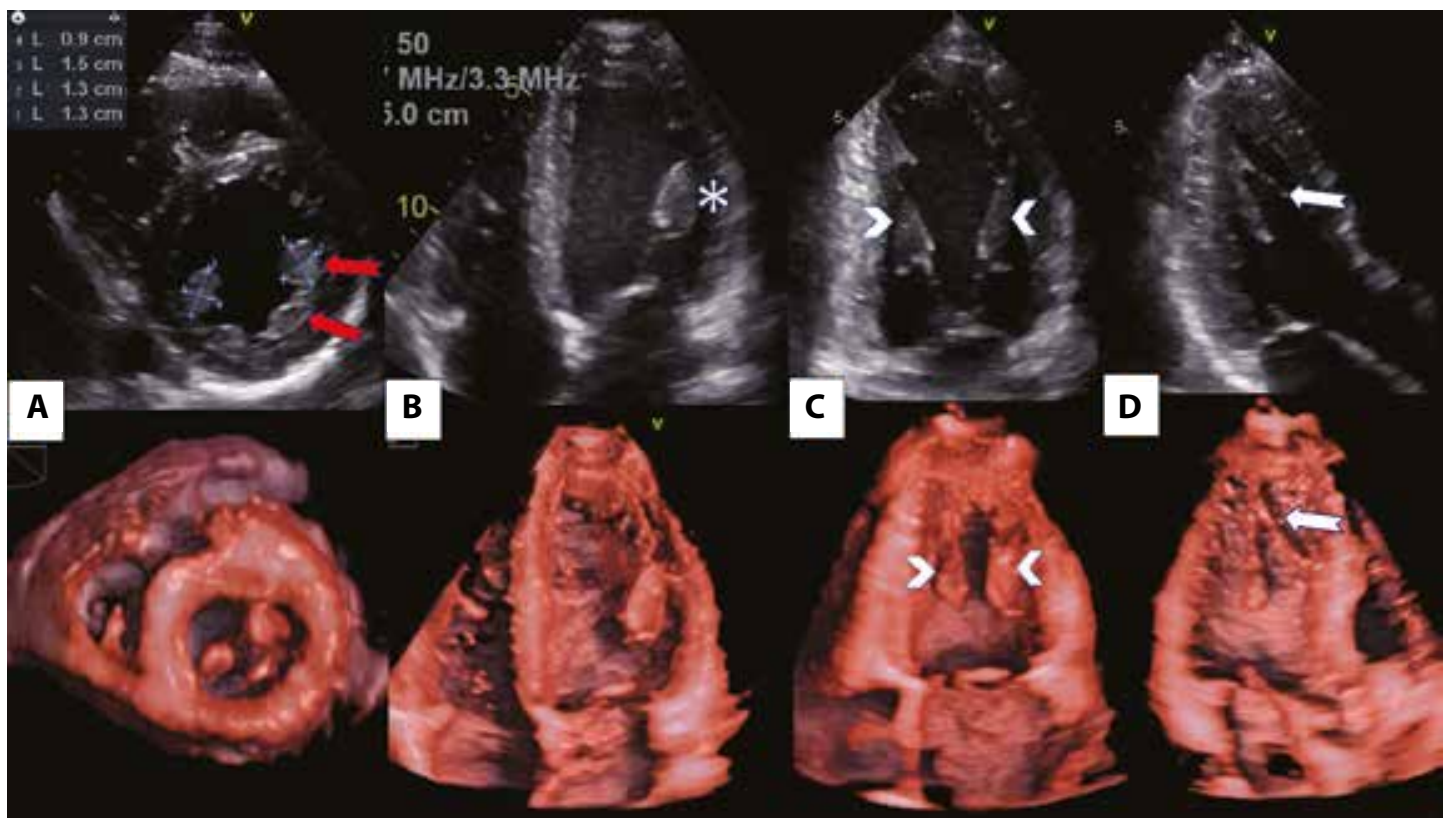

Figure 1. Comparative 2D and 3D transthoracic echocardiogram images (top and bottom panels respectively). A. Parasternal short- axis view demonstrating the measurement of papillary muscles and a double headed anterolateral papillary muscle (red arrows). B. Apical 4-chamber view showing the prominent anterolateral papillary muscle (asterisk). C. Apical 2-chamber view showing the hypertrophied papillary muscles (arrowheads). D. Apical 3-chamber view demonstrating a false chordae tendineae (white arrow)

result; (2) the absence of intraventricular gradient; (3) the absence of arrhythmias on $48 \mathrm{~h}$ Holter monitoring, (4) the absence of both syncope and exercise-induced ventricular tachycardia; (5) the exclusion of Fabry disease and the most common sarcomeric mutations. Further studies are needed to better understand the clinical relevance of this morphological abnormality.

\section{Supplementary material}

Supplementary material is available at https://journals. viamedica.pl/kardiologia_polska.

\section{Article information}

Conflict of interest: None declared.

Open access: This article is available in open access under Creative Common Attribution-Non-Commercial-No Derivatives 4.0 International (CC BY-NC-ND 4.0) license, allowing to download articles and share them with others as long as they credit the authors and the publisher, but without permission to change them in any way or use them commercially. For commercial use, please contact the journal office at kardiologiapolska@ptkardio.pl.

How to cite: Zulema C, Leyva M, Arroyo-Rodruguez C, et al. Isolated papillary muscle hypertrophy in a professional soccer player: the end of an athlete's career? Kardiol Pol. 2021; 79(10): 1147-1148, doi: 10.33963/KP.a2021.0063.

\section{REFERENCES}

1. Pelliccia A, SharmaS, Gati S, et al. ESC Scientific Document Group. 2020 ESC Guidelines on sports cardiology and exercise in patients with cardiovascular disease. Eur Heart J.2021;42(1):17-96, doi: 10.1093/eurheartj/ehaa605, indexed in Pubmed: 32860412.

2. Ommen SR, Mital S, Burke MA, et al. 2020 AHA/ACC Guideline for the diagnosis and treatment of patients with hypertrophic cardiomyopathy: a report of the American College of Cardiology/American Heart Association Joint Committee on Clinical Practice Guidelines. Circulation. 2020; 142(25): e558-e631, doi: 10.1161/CIR.0000000000000937, indexed in Pubmed: 33215931.

3. Kobashi A, Suwa M, Ito T, et al. Solitary papillary muscle hypertrophy as a possible form of hypertrophic cardiomyopathy. Jpn Circ J. 1998; 62(11): 811-816, doi: 10.1253/jcj.62.811, indexed in Pubmed: 9856596.

4. Uhm JS, Youn JC, Lee HJ, et al. Accessory papillary muscles and papillary muscle hypertrophy are associated with sudden cardiac arrest of unknown cause. Int J Cardiol. 2015; 197:285-291, doi: 10.1016/j.jicard.2015.06.097, indexed in Pubmed: 26142977.

5. Correia AS, Pinho T, Madureira AJ, et al. Isolated papillary muscle hypertrophy: a variant of hypertrophic cardiomyopathy? Do not miss a hypertrophic cardiomyopathy. Eur Heart J Cardiovasc Imaging. 2013; 14(3):296, doi: 10.1093/ehjci/jes195, indexed in Pubmed: 23002198. 